\title{
Antibacterial Activity of Honey on Staphylococcus aureus Isolated from Wounds
}

\author{
Anima Shrestha ${ }^{1 *}$ and Milan Kandel ${ }^{2}$ \\ ${ }^{1}$ Department of Microbiology, Tri-Chandra College, Tribhuvan University, Nepal \\ ${ }^{2}$ Department of Microbiology, St. Xavier's College, Tribhuvan University, Nepal \\ *Corresponding Author \\ shrestha_anima@hotmail.com
}

\begin{abstract}
Honey, a natural product of bees, has been used as nutritious food as well as medicine in ancient time for treatment of wound and burns. It has a healing property and is also very useful in the treatment of infection caused by antibiotic-resistant bacteria. The study was carried out to compare the antibacterial activity of three different honey obtained from Apis mellifera, A.serena and A.dorsata The study period was from February to June 2010. Fifty-two wound swabs were obtained from private clinics and hospitals. Laboratory work was done in Microbiology laboratory of St. Xavier's College, Kathmandu, Nepal. Antibacterial activity of honey samples on 38 isolates of $S$. aureus showed that honey obtained from wild species $A$. dorsata was the most effective among the honey tested.
\end{abstract}

\section{Keyword}

Antibacterial activity, Apis dorsata, honey, Staphylococcus aureus

\section{Introduction}

Honey is a nutrition-rich food consumed by humans all over the world. Besides, the medicinal properties of honey have been known since ancient times. Honey has been used in folkloric medicine in different cultures throughout human history. Honey has been useful in the treatment of surgical wounds, burns and decubitus ulcers, and the antibacterial and antifungal properties of honey are well documented (Subrahmanyam 1991). Honey is also known to show antimicrobial activity against several Gram-positive and Gramnegative bacteria (Farouk et al., 1988; Russel et al., 1990; Subrahmanyam 1991; Willix, et al.,1992).

Honey is produced from different sources, and its antimicrobial activity varies significantly with origin (Molan 1992). The antibacterial activity of honey has been attributed by physical factors such as osmolarity (Molan 1992; Weston 2000), acidity (Bogdanov 1997; Mato, et al.,2000) and chemical factors (Al Somal, et al.,1994; Weston 2000). Nzeako and Hamdi (2000) reported that commercial honey had antimicrobial effects against Staphylococcus aureus, Escherichia coli and Pseudomonas aeruginosa. All the bacteria isolated from the burn and wounds in the study of Subramanyam, et al.,(2001) failed to grow at a concentration of $30 \%$ honey.

The antibacterial activity of honey is mainly due to inhibines in honey. These inhibines are hydrogen peroxide, flavonoids, and phenolic acids, plus many other unidentified inhibines. Some reasons for this have been suggested: shrinkage disruption of the bacterial cell wall due to osmotic effect of the sugar content; induction of an unfavourable environment with low water activity, thereby inhibiting bacterial growth; and a low $\mathrm{pH}$ of 3.6 and the fermentation of honey, producing alcohol (Subrahmanyam, et al.,2001). Honey acts like a highly viscous barrier preventing bacterial penetration and colonization of the wound surface. This study was undertaken to determine the antibacterial activity of three different honey samples produced by three different honey-bee species - A. mellifera, A. serena and A. dorsata upon Staphylococcus aureus isolated from the wound infections. The outcome of the study would be useful in the selection of a type of honey for the treatment of wound infection even in the case of the infection due to antibiotic-resistant $S$. aureus. 


\section{Methodology \\ Collection of honey}

Three honey samples produced by three different species of honey-bees viz. A. mellifera, A. serena and $A$. dorsata were collected from different sources.

\section{Collection of pus and swab sample of infected wounds}

The samples were taken from patients visiting private clinics and hospitals after taking informed consent from patients. Fifty-two samples in total were taken. The samples were taken before the treatment of the infection with antibiotics. The samples were collected by swabbing the surface of an infected wound by sterile swab and moistened the swab by placing it on Amies transport media (Collee et al., 1996; Cheesbrough 1998), transported to the Microbiology laboratory of St. Xavier's College, Kathmandu and processed immediately.

\section{Processing of sample and identification of isolates}

The pus and swab samples were inoculated on Mannitol Salt Agar (MSA) for the selective isolation of Staphylococcus aureus. MSA is a selective medium for recovering $\mathrm{S}$. aureus as it ferments mannitol with the production of acid, which is indicated by the yellow coloration of media and can grow on agar containing 7-10\% of sodium chloride (Cheesbrough 1998). The organisms were further confirmed by Gram staining, Catalase and Coagulase test of the organisms subcultured on basal medium (Nutrient Agar). Gram-positive cocci in clusters, Catalase positive and Coagulase positive bacteria were confirmed as $S$. aureus and then proceeded for sensitivity assay (Collee 1996). Among 52 samples processed, 38 were confirmed with $S$. aureus.

\section{Assay of honey against S. aureus}

Crude, unprocessed and undiluted honey samples from A. mellifera, A. serena and A. dorsata were taken for the study. Antibacterial activity was analysed by the agar well diffusion technique (Collee 1996; Cheesbrough 1998) on MuellerHinton Agar (MHA). The broth cultures of $S$. aureus of $0.5 \mathrm{Mc}$ Farland Turbidity standards were inoculated by swabbing on MHA, and four wells were made with the help of sterile cork borer of $5 \mathrm{~mm}$ diameter. $50 \mu \mathrm{L}$ of three honey samples were dispensed in three different wells and the same volume of sterile water in one well. The plates were incubated overnight at 37 ${ }^{\circ} \mathrm{C}$ aerobically after complete diffusion of honey under refrigerated condition. After overnight incubation, the zones of inhibition on MHA plates around the wells were observed, and the diameters of the inhibition zones were measured.

Antibiotic sensitivity test of the isolated S. aureus

The broth cultures of $S$. aureus of 0.5 Mc Farland Turbidity standards were inoculated by swabbing on MHA. The refrigerated antibiotic discs were kept at room temperature for about 30 minutes before use. Antibiotic discs of Methicillin (5 $\mathrm{mcg}$ ), Tetracyclin (30 mcg), Ciprofloxacin (5 $\mathrm{mcg})$, Vancomycin $(30 \mathrm{mcg}$ ) and Co-trimoxazole $(25 \mathrm{mcg})$ were of Hi-media laboratory Pvt. Ltd. India. An antibiotic sensitivity test was performed using the modified Kirby-Bauer Disc Diffusion technique (Collee 1996; Cheesbrough 1998).

\section{Results and Discussion}

Out of 52 swab samples processed, $S$. aureus was isolated from 38 samples. The isolates were tested for the antibacterial activity of honey obtained from $A$. mellifera, A. serena and A. dorsata. The antibacterial activity of the honey samples against $S$. aureus isolates in the study is presented in Table1.

In the present study, the means of a diameter of inhibition zones of $38 \mathrm{~S}$. aureus isolates due to A. mellifera, A. serena and A. dorsata were found to be $13 \mathrm{~mm}, 8 \mathrm{~mm}$ and $22 \mathrm{~mm}$ respectively. Thus, honey obtained from $A$. dorsata (wild bee species) was found to be the most effective against S. aureus isolates from infected wounds.

The outcome of the study is also supported by the inhibition of the growth of $S$. aureus, Escherichia coli, Proteus mirabilis, and Pseudomonas (Willix et al.,1992). The past studies done for the antibacterial activity of honey were not found to be correlated with the bee-species, but with the type of honey sample and with the plant source from which nectar has been collected. In a study done in Turkey (Selcuk and Nevin 2002), most honey samples at a concentration of above $50 \%$ were found to have an inhibitory effect on $S$. aureus.

Antibiotic sensitivity test of the isolated $S$. aureus was also performed using the antibiotics 
Nepal Journal of Science and Technology (NJST) (2020), 19(1)

Table 1. Inhibition pattern of $\mathrm{S}$. aureus isolates by crude honey samples

\begin{tabular}{|c|c|c|c|}
\hline \multirow[b]{2}{*}{ Isolated S. aureus } & \multicolumn{3}{|c|}{ Zone of inhibition (diameter in $\mathrm{mm}$ ) due to honey obtained from } \\
\hline & A. mellifera & A. serena & A. dorsata \\
\hline 1 & 12 & 9 & 20 \\
\hline 2 & 19 & 12 & 15 \\
\hline 3 & 13 & 10 & 18 \\
\hline 4 & 11 & 5 & 19 \\
\hline 5 & 14 & 6 & 22 \\
\hline 6 & 13 & 8 & 25 \\
\hline 7 & 10 & 8 & 24 \\
\hline 8 & 12 & 9 & 24 \\
\hline 9 & 13 & 10 & 20 \\
\hline 10 & 13 & 10 & 13 \\
\hline 11 & 14 & 9 & 17 \\
\hline 12 & 12 & 7 & 17 \\
\hline 13 & 12 & 7 & 25 \\
\hline 14 & 15 & 7 & 27 \\
\hline 15 & 16 & 4 & 21 \\
\hline 16 & 12 & 6 & 21 \\
\hline 17 & 13 & 7 & 19 \\
\hline 18 & 14 & 9 & 18 \\
\hline 19 & 15 & 9 & 20 \\
\hline 20 & 17 & 6 & 19 \\
\hline 21 & 18 & 12 & 24 \\
\hline 22 & 9 & 5 & 19 \\
\hline 23 & 18 & 13 & 30 \\
\hline 24 & 13 & 9 & 25 \\
\hline 25 & 14 & 10 & 22 \\
\hline 26 & 8 & 3 & 20 \\
\hline 27 & 8 & 5 & 23 \\
\hline 28 & 10 & 5 & 24 \\
\hline 29 & 14 & 11 & 26 \\
\hline 30 & 15 & 11 & 23 \\
\hline 31 & 14 & 6 & 25 \\
\hline 32 & 13 & 8 & 24 \\
\hline 33 & 13 & 9 & 22 \\
\hline 34 & 15 & 6 & 27 \\
\hline 35 & 11 & 10 & 25 \\
\hline 36 & 11 & 8 & 22 \\
\hline 37 & 12 & 8 & 21 \\
\hline 38 & 11 & 7 & 20 \\
\hline Mean & 13 & 8 & 22 \\
\hline
\end{tabular}

Methicillin (5 mcg), Tetracyclin (30 mcg), Ciprofloxacin $(5 \mathrm{mcg})$, Vancomycin $(30 \mathrm{mcg})$ and Co-trimoxazole $(25 \mathrm{mcg})$. The most effective antibiotic against $S$. aureus tested was found to be Vancomycin with $100 \%$ efficacy. $57.9 \%$ of the isolates were sensitive to Tetracyclin, $42.1 \%$ of the isolates were sensitive to Ciprofloxacin, $34.2 \%$ were sensitive to Methicillin, and only $15.8 \%$ were sensitive to Co-trimoxazole. (Table 2)
The antibiotic sensitivity pattern of the isolated $S$. aureus showed that most of the isolates were sensitive to vancomycin and tetracycline, but with other antibiotics, a considerable number of the isolates were resistant too. The effectiveness of the honey sample against the antibiotic-resistant organisms helps to treat the open wounds due to burning, abrasions, incision infected with $S$. aureus. 
Nepal Journal of Science and Technology (NJST) (2020), 19(1)

Table 2. Antibiotic sensitivity pattern of $\mathrm{S}$. aureus isolates

\begin{tabular}{lllllll}
\hline \multirow{2}{*}{ Antibiotics used } & Sensitive & \multicolumn{2}{c}{ Intermediate } & \multicolumn{2}{l}{ Resistant } \\
\cline { 2 - 7 } & Number & Percentage & Number & Percentage & Number & Percentage \\
\hline METHICILLIN & 13 & 34.2 & 15 & 39.5 & 10 & 26.3 \\
Tetracyclin & 22 & 57.9 & - & - & 16 & 42.1 \\
Ciprofloxacin & 16 & 42.1 & 6 & 15.8 & 16 & 42.1 \\
Vancomycin & 38 & 100 & 0 & 0 & 0 & 0 \\
Co-trimoxazole & 6 & 15.8 & 13 & 34.2 & 19 & 50.0 \\
\hline
\end{tabular}

Conclusion
Honey obtained from wild species of bee might be useful for the local application in the treatment of wounds infected by $S$. aureus.

\section{Acknowledgement}

The authors are thankful to St. Xavier's College, Kathmandu for providing laboratory facilities, to all the patients for providing samples for study.

\section{References}

Al Somal, N., K.E, Coley, P.C. Molan and B.M. Hacook, 1994. Susceptibility of Helicobacter pylori to the antibacterial activity of manuka honey. J, Royal Soc, Med. 87: 1-3

Bogdanov, S., 1984. Characterization of antibacterial substances in honey, Lebensm, Wiss. u. Technol. 30: 748-753.

Cheesbrough, M., 2000. District Laboratory Practice in Tropical Countries. Low Price Edition. Cambridge University Press. 80-85, 132-143.

Collee, JG, Fraser, AG, Marmion, BP, Simmons, A. 1996. Mackie and Mc Cartney Practical Medical Microbiology. 14 ${ }^{\text {th }}$ Edition. Churchill Livingstone. 113-130.

Farouk, A., T. Hassan, H. Kashif, S.A. Khalid, I. Mutaawali and M. W ADI. 1988. Studies on Sudanese bee honey: Laboratory and Clinical Evaluation. Int, J. Crude. Drug. Res. 26: 3, 161-168.
Molan, P.C.1992. The antibacterial activity of honey. Bee World. 73: 5-28, 59-76.

Russel, K.M., P.C. Molan, A.L. Wilkins and P.T. Holland. 1990. Identification of some antibacterial constituents of New Zealand manuka honey. J. Agric. Food Chem. 38: 1013.

Selcuk, H. and Nevin, K., 2002. Investigation of antimicrobial effect of honey collected from various regions of turkey. Pakistan Journal of Biological Sciences. 5 (3): 325-328.

Subrahmanyam, M., Hemmady, A.R. and Pawar, S.G. 2001. Antibacterial activity of honey on bacteria isolated from wounds. Annals of Bums and Fire Disasters. 14 (1), 198-201.

Subrahmanyam, M., 1991.Topical application of honey in the treatment of burns. Br. J. Surg.78: 497-498.

Weston, R.J., K.R. Mitchell, and K.L. Allen. 2000. Antibacterial phenolic components of New Zealand manuka honey. Food Chem., 64: 295-301.

Willix, D.J., Molan, P.C., and Harfoot, C.G. 1992. A comparison of the sensitivity of wound-infecting species of bacteria to the antibacterial activity of manuka honey and other honey. Journal of Applied Bacterial. 73 (5), 388-394. 